\title{
PENGARUH MODEL PEMBELAJARAN INKUIRI TERBIMBING TERHADAP HASIL BELAJAR FISIKA SISWA KELAS VIII SMP NEGERI 4 METRO SEMESTER GENAP TAHUN PELAJARAN 2013/2014
}

\author{
Laela Ngasarotur Risfiqi Khotimah \\ Partono \\ Pendidikan Fisika FKIP Universitas Muhammadiyah Metro \\ Email: partono66@gmail.com
}

\begin{abstract}
The aims of this research is to find the effect of guided inquiry learning model on learning outcomes physics eighth grade students of SMP N 4 Metro semester of academic year 2013/2014. The sample was VIIID as VIIIF as a control class and experimental class were selected by cluster random sampling. The study design used was Posttest-Only Control Design and researchinstruments in the form of sheets of observations and questions. Technical analysis of the data use normality test, homogeneity, test the similarity of two average, and two different test average.

The results showed that the improvement of learning outcomes learning physics class experiments using guided inquiry learning model is higher than the control class students. From the calculation, the value of $t=2.18$ is higher than the value table $=2.02$ at significance level $\alpha=5 \%$. Therefore, it can concluded that the model of guided inquiry learning effect on learning outcomes physics eighth grade students of SMP N 4 Metro semester of academic year 2013/2014. The success of learning during the learning process using guided inquiry model of learning because students can more freely in finding the concept it self and can connect between the knowledge possessed by the results they found in the experiments, so that influenced on learning outcomes.
\end{abstract}

Keywords: Guided Inquiry Learning Model, Learning Outcomes

PENDAHULUAN

Ilmu Pengetahuan Alam (IPA) Pendidikan IPA diharapkan dapat adalah suatu ilmu yang mempelajari menjadi wahana bagi peserta didik 
untuk mempelajari diri sendiri dan alam sekitar, serta menerapkannya dalam kehidupan sehari-hari. Proses pembelajarannya menekankan pada pemberian pengalaman langsung untuk mengembangkan kompetensi agar memahami alam sekitar secara ilmiah Pembelajaran IPA seharusnya dapat memberikan kesempatan siswa bereksplorasi, berpikir, dan memperoleh kesempatan berdiskusi, berkomunikasi, dan berinteraksi dengan teman sejawat juga bekerja sama secara kelompok. Untuk itu pembelajaran IPA hendaknya menggunakan model pembelajaran yang dapat membawa siswa ke dalam situasi yang nyata, di mana siswa dapat melihat dan membuktikan sendiri pengetahuan berdasarkan fakta yang ada serta memperoleh pengalaman konkret.

Hasil survei yang dilakukan pada tanggal 25 Oktober 2013 di SMP Negeri 4 Metro diperoleh data tentang hasil belajar IPA, siswa kelas VIII semester genap tahun pelajaran 2012/2013. Dari data yang diperoleh, terlihat bahwa banyak siswa yang masih memiliki hasil belajar yang belum tuntas.
Pra survei lebih lanjut dilakukan untuk mengamati kegiatan guru dalam proses pembelajaran IPA. Berdasarkan hasil observasi di kelas VIII SMP Negeri 4 Metro yang berjumlah 7 kelas, menunjukkan bahwa pembelajaran berjalan dengan cukup baik, guru menyampaikan dan menjelaskan materi di depan kelas sedangkan kegiatan siswa yaitu mendengarkan dan menulis materi yang disampaikan oleh guru, yang kemudian dilanjutkan dengan memberikan soal latihan kepada siswa. Namun pelaksanaan pembelajaran yang dilakukan kurang sesuai, sehingga siswa menjadi bosan dan kurang fokus pada pembelajaran serta tidak langsung melakukan pengamatan dan pengalaman sendiri dari permasalahan yang ada. Dengan tidak terlibatnya siswa dalam pembelajaran membuat siswa menjadi kurang memahami materi yang telah dijelaskan dan menyebabkan kemampuan siswa tidak berkembang secara optimal.

Dilihat dari masalah yang ditemukan, perlu dilakukan upaya untuk meningkatkan kemampuan dan hasil belajar siswa. Pembelajaran yang tepat hendaknya dapat membawa 
siswa ke dalam situasi yang nyata, di mana siswa dapat melihat dan membuktikan sendiri pengetahuan berdasarkan fakta yang ada serta memperoleh pengalaman konkret, yaitu dengan menggunakan model pembelajaran inkuiri. Tujuan dari pembelajaran ini adalah pada pembentukan insan yang terdidik secara utuh dalam bentuk hasil belajar.

Menurut Trianto (2010) Inkuiri merupakan bagian inti dari kegiatan pembelajaran berbasis kontekstual. Pengetahuan dan keterampilan yang diperoleh siswa diharapkan bukan hasil mengingat seperangkat fakta-fakta, tetapi hasil dari menemukan sendiri. Sedangkan menurut Hanafiah (2010), inkuiri adalah suatu rangkaian kegiatan pembelajaran yang melibatkan secara maksimal seluruh kemampuan peserta didik untuk mencari dan menyelidiki secara sistematis, kritis, dan logis sehingga mereka dapat menemukan sendiri pengetahuan, sikap dan keterampilan sebagai wujud adanya perubahan prilaku.

Sehingga pembelajaran inkuiri merupakan kegiatan pembelajaran yang melibatkan secara maksimal seluruh kemampuan siswa untuk mencari dan menyelidiki sesuatu (benda, manusia atau pristiwa) secara sistematis, kritis, logis, analitis sehingga mereka dapat merumuskan sendiri penemuannya dengan penuh percaya diri.

Menurut Hamalik (2011) bahwa Pengajaran berdasarkan inkuiri adalah suatu strategi yang berpusat pada siswa di mana kelompok siswa inkuiri ke dalam suatu isu atau mencari jawabanjawaban terhadap isi pertanyaan melalui suatu prosedur yang digariskan secara jelas dan struktural kelompok.

Berdasarkan pendapat di atas, peneliti dipilih metode inkuiri terbimbing, karena guru berperan dalam menentukan permasalahan dan tahap-tahap pemecahannya, dan siswa menyelesaikan masalah secara diskusi kelompok dan menarik kesimpulan secara mandiri. Sehingga inkuiri terbimbing dapat diartikan sebagai salah satu model pembelajaran berbasis inkuiri/penemuan yang menyajikan masalah dan penyelesaian dari masalah ditentukan guru.

Belajar bukan hanya mengingat tapi juga mengalami. Bukti bahwa seseorang telah melakukan kegiatan belajar adalah adanya perubahan tingkah laku. 
Abdurrahman (2003) menyatakan bahwa hasil belajar adalah kemampuan yang diperoleh anak setelah melalui kegiatan belajar. Belajar itu sendiri merupakan suatu proses dari seseorang yang berusaha untuk memperoleh suatu bentuk perubahan prilaku yang relatif menetap. Dalam kegiatan belajar yang terprogram dan terkontrol yang disebut kegiatan pembelajaran atau kegiatan instruksional, tujuan belajar telah ditetapkan lebih dahulu oleh guru. Anak yang berhasil dalam belajar ialah yang berhasil mencapai tujuan-tujuan pembelajaran atau tujuan instruksional.

Menurut Dimyati \& Mujiono (2006), belajar merupakan hasil dari suatu interaksi tindak belajar dan tindak mengajar. Sedangkan menurut Sanjaya (2008) menyatakan bahwa hasil belajar merupakan gambaran kemampuan siswa dalam memenuhi suatu tahapan pencapaian pengalaman belajar dalam satu kompetensi dasar. Jadi dapat disimpulkan bahwa hasil belajar adalah kemampuan-kemampuan yang dimiliki siswa setelah ia menerima pengalaman dari proses pembelajaran. Hasil belajar digunakan oleh guru untuk dijadikan ukuran atau kriteria dalam mencapai suatu tujuan pendidikan yang ditunjukkan dengan nilai tes yang diberikan oleh guru setelah selesai memberikan materi pelajaran pada satu pokok bahasan.

\section{METODE}

Penelitian ini menggunakan desain Posttest-Only Control Design Desain ini menggunakan 2 kelompok, yaitu kelas kontrol dan kelas eksperimen. Kelas eksperimen adalah kelas yang mendapat model pembelajaran inkuiri terbimbing saat pembelajaran sedangkan kelompok kontrol adalah kelompok pengendali yaitu kelas yang tidak mendapat perlakuan model pembelajaran inkuiri terbimbing. Menurut Sugiyono (2011:112) bahwa Posttest-Only control Design digambarkan sebagai berikut:

\begin{tabular}{|lll|}
\hline $\mathbf{R}$ & $\mathbf{X}$ & $\mathbf{O}_{2}$ \\
$\mathbf{R}$ & & $\mathbf{O}_{4}$ \\
\hline
\end{tabular}

Gambar.1 Desain Eksperimen

Dalam desain eksperimen ini terdapat dua kelompok yang masing masing dipilih secara teknik cluster random sampling. Kelompok pertama sebagai kelas eksperimen dan 
kelompok dua sebagai kelas kontrol. kelas eksperimen lebih tinggi daripada Pengaruh adanya perlakuan model kelas kontrol.

pembelajaran inkuiri terbimbing di analisis dengan uji beda, menggunakan uji statistik t-test. Kalau terdapat perbedaan nilai hasil belajar antara kelompok eksperimen dan kelompok kontrol, maka perlakuan yang diberikan berpengaruh secara signifikan terhadap hasil belajar.

\section{HASIL DAN PEMBAHASAN}

Berdasarkan penelitian yang telah dilakukan diperoleh data kuantitatif dan data kualitatif. Data kuantitatif meliputi data hasil belajar siswa setelah melakukan tes akhir (posttest) sedangkan data kuantitatif meliputi hasil observasi.

Dapat dilihat data nilai hasil belajar (posttest) siswa kelas eksperimen berjumlah 22 dan siswa kelas kontrol berjumlah 23.

Berdasarkan analisis ditunjukkan pada uji perbedaan dua ratarata bahwa pada taraf signifikansi 5\% $t_{\text {hitung }}>t_{\text {tabel }}$ atau dengan hasil perhitungan statistik diperoleh 2,18> 2,02. Berdasarkan analisis tersebut menunjukkan bahwa hasil belajar IPA
Perbandingan rata-rata hasil belajar siswa berdasarkan (kelas eksperimen dan kelas kontrol) adalah $84,36>77,70$. Hal ini menunjukkan bahwa hasil belajar siswa pada kelas eksperimen lebih baik dari pada siswa kelas kontrol. Ini juga terlihat dari ratarata indikator keberhasilan siswa dalam menyelesaikan soal pada kelas eksperimen adalah $86,33 \%$ dan kelas kontrol adalah 76,67\%. Artinya model pembelajaran inkuiri terbimbing berpengaruh terhadap hasil belajar fisika siswa. Karena kelompok eksperimen menggunakan model pembelajaran inkuiri terbimbing di mana dalam pembelajarannya siswa terlibat langsung sehingga termotivasi untuk belajar. Selain itu, siswa diberi kesempatan untuk berpartisipasi dalam pembelajaran dan guru hanya membimbing siswa. Selanjutnya pada proses pembelajaran di kelas siswa yang belajar dengan model pembelajaran inkuiri terbimbing lebih bebas dalam menemukan konsep sendiri. Pada kegiatan praktikum siswa dapat mengembangkan konsep yang 
mereka buat dengan pengetahuannya sendiri dan sesama temannya.
Gambaran perbandingan hasil belajar antara kelas eksperimen dan kelas kontrol dilihat pada gambar 2.

Tabel 1. Nilai posttest Pada Kelas Eksperimen Dan Kelas Kontrol.

\begin{tabular}{|c|c|c|c|c|c|c|}
\hline \multirow[b]{2}{*}{ No } & \multirow[b]{2}{*}{ Indikator Soal } & \multirow[b]{2}{*}{ Skor } & \multicolumn{2}{|c|}{ Kelas Eksperimen } & \multicolumn{2}{|c|}{ Kelas Kontrol } \\
\hline & & & $\begin{array}{l}\text { Rata-rata } \\
\text { Skor }\end{array}$ & $\begin{array}{l}\text { Indikator } \\
\text { Pencapai } \\
\text {-an }(\%)\end{array}$ & $\begin{array}{l}\text { Rata-rata } \\
\text { Skor }\end{array}$ & $\begin{array}{l}\text { Indikator } \\
\text { Pencapai } \\
\text {-an }(\%)\end{array}$ \\
\hline 1 & Menjelaskan pengertian getaran & 5 & 4.818 & 96.36 & 4.304 & 86.09 \\
\hline 2 & $\begin{array}{l}\text { Menuliskan contoh getaran dalam } \\
\text { kehidupan sehari-hari }\end{array}$ & 5 & 4.909 & 98.18 & 3.304 & 66.09 \\
\hline 3 & $\begin{array}{l}\text { Menjelaskan pengertian amplitudo, } \\
\text { frekuensi, dan periode getaran }\end{array}$ & 15 & 11.82 & 78.79 & 10 & 66.67 \\
\hline 4 & $\begin{array}{l}\text { Menentukan pergerakan bandul saat } \\
\text { bergetar }\end{array}$ & 15 & 10.14 & 67.58 & 10.43 & 69.57 \\
\hline 5 & $\begin{array}{l}\text { Menentukan besarnya frekuensi } \\
\text { getaran pada sebuah bandul }\end{array}$ & 20 & 16.09 & 80.45 & 16.26 & 81.3 \\
\hline 6 & $\begin{array}{l}\text { Menentukan besarnya periode, dan } \\
\text { frekuensi suatu getaran }\end{array}$ & 20 & 18.14 & 90.68 & 15.65 & 78.26 \\
\hline 7 & $\begin{array}{l}\text { Menentukan hubungan periode dan } \\
\text { frekuensi suatu getaran }\end{array}$ & 20 & 18.45 & 92.27 & 17.74 & 88.7 \\
\hline & Jumlah & 100 & 84.36 & 85,9 & 77.70 & 76,67 \\
\hline
\end{tabular}

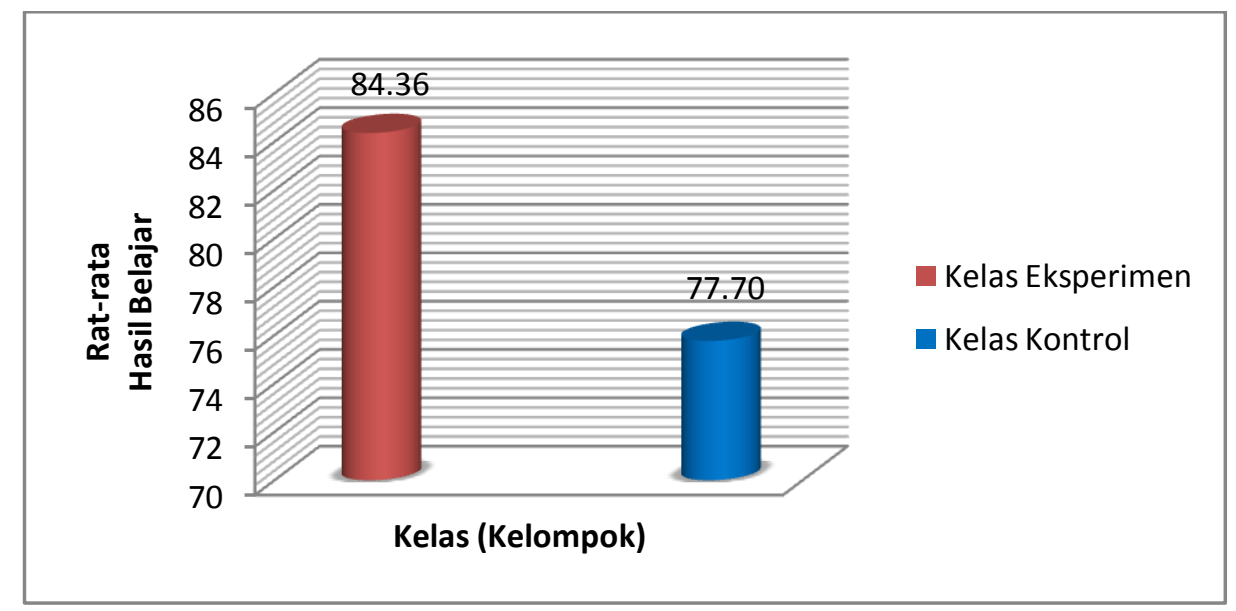

Gambar 2. Perbandingan hasil belajar antara kelas eksperimen dan kelas kontrol

Data observasi ini menjelaskan terbimbing dalam proses pembelajaran. tentang terlaksananya langkah-langkah Dari hasil observasi yang telah kegiatan dengan model inkuiri dilakukan oleh observer didapat data 
kualitatif yang dijelaskan pada tabel 2.

Berdasarkan hasil pengamatan tersebut

diketahui bahwa pengaruh model pembelajaran inkuiri terbimbing juga dapat dilihat dari aktivitas siswa saat pembelajaran.

Berdasarkan pengamatan saat proses pembelajaran, terlihat bahwa suasana belajar kelas eksperimen yang pembelajarannya menggunakan model pembelajaran inkuiri terbimbing menjadi hidup dan aktif. Pembelajaran ini membuat siswa mendapatkan pemahaman yang lebih baik dan siswa lebih tertarik untuk mengetahuinya. Hal ini seperti yang diungkapkan Rahmatsyah \& Simamora (2011) dalam penelitiannya yang menyatakan bahwa model pembelajaran inkuiri terbimbing memiliki tahapan pembelajaran yang membangkitkan keaktifan siswa sehingga selain aktivitas meningkat, hasil belajar juga meningkat.

Interaksi melalui kegiatan diskusi juga akan melatih siswa, untuk mengembangkan kepekaan sosialnya, karena siswa memiliki lebih banyak kesempatan untuk meningkatkan komunikasi dan kemampuan berpikir. Kegiatan diskusi tersebut terlihat saat siswa mengamati dan mencatat waktu yang dibutuhkan bandul untuk melakukan 10 getaran, kemudian saling bekerjasama dalam melakukan perhitungan dan membuktikan konsep yang ada. Ini dibuktikan melalui pengamatan observer pada catatan lapangan saat pembelajaran inkuiri terbimbing berlangsung. Kondisi seperti ini membuat siswa tidak merasa jenuh dalam proses belajar mengajar sehingga berpengaruh terhadap hasil belajar siswa. Ada pula beberapa faktor pendukung yang menyebabkan model pembelajaran inkuiri terbimbing berpengaruh terhadap hasil belajar fisika siswa diantaranya yaitu: 1) Terlaksananya langkah-langkah kegiatan dengan model inkuiri terbimbing dalam proses pembelajaran, 2) Permasalahan yang disajikan dalam LKS mampu membangkitkan minat dan rasa ingin tahu siswa, 3) Alat-alat praktikum yang menunjang kegiatan pembelajaran, 4) Adanya kesempatan siswa untuk mengkomunikasikan hasil diskusi.

Berdasarkan uraian menunjukkan bahwa perlakuan yang berbeda menyebabkan terjadinya hasil akhir yang berbeda antara kelas eksperimen dengan kelas kontrol. Dengan 
demikian, ternyata terbukti bahwa Saran

model pembelajaran inkuiri terbimbing berpengaruh signifikan terhadap hasil belajar.

\section{PENUTUP}

\section{Kesimpulan}

Berdasarkan analisis data dan pengujian hipotesis dalam penelitian ini, maka dapat disimpulkan bahwa:

- Model pembelajaran inkuiri terbimbing berpengaruh signifikan terhadap hasil belajar fisika siswa kelas VIII SMP Negeri 4 Metro semester genap Tahun Pelajaran 2013/2014.

- Ada beberapa faktor yang menyebabkan model pembelajaran inkuiri terbimbing berpengaruh terhadap hasil belajar fisika siswa diantaranya yaitu: Terlaksananya langkah-langkah kegiatan dengan model inkuiri terbimbing dalam proses pembelajaran, permasalahan yang disajikan dalam LKS mampu membangkitkan minat dan rasa ingin tahu siswa, alat-alat praktikum yang menunjang kegiatan pembelajaran dan adanya kesempatan siswa untuk mengkomunikasikan hasil diskusi.
Sebagai tindak lanjut dari hasil penelitian ini maka peneliti dapat memberikan beberapa saran sebagai berikut:

- Bagi guru fisika hendaknya model pembelajaran inkuiri terbimbing dapat dijadikan alternatif untuk meningkatkan hasil belajar siswa.

- Bagi siswa diharapkan lebih aktif lagi untuk mengikuti pelajaran IPA Terpadu agar dapat mencapai pemahaman yang bagus atau bahkan yang lebih.

- Berdasarkan penelitian terdapat beberapa keterbatasan di mana penelitian ini hanya terbatas pada konsep getaran dan hasil belajar dalam ranah kognitif. Oleh sebab itu, diharapkan adanya penelitian lebih lanjut mengenai model pembelajaran inkuiri terbimbing terhadap hasil belajar dalam ranah afektif dan psikomotor serta diaplikasikan pada konsep-kosep fisika lainnya.

\section{DAFTAR PUSTAKA}

Abdurrahman, Mulyono. 2003. Pendidikan Bagi Anak 
Berkesulitan Belajar. Jakarta:

Rineka Cipta

Dimyati dan Mudjiono. 2006. Belajar dan Pembelajaran. Jakarta: Rineka Cipta

Hamalik, Oemar. 2011. Proses belajar mengajar. Jakarta : Bumi Aksara

Hanafiah, Nanang, dkk. 2010. Konsep Strategi Pembelajaran. Bandung: PT Refika Aditama

Rahmatsyah dan Harni Simamora. 2011. Pengaruh Keterampilan Proses Sains Melalui Model Pembelajaran Inkuiri Terbimbing Terhadap Hasil Belajar Siswa Pada Materi Pokok Gerak di Kelas VII SMP. Jurnal Penelitian Inovasi Pembelajaran Fisika. Vol 3. 17

Sugiyono. 2011. Metode Penelitian Pendidikan. Bandung: Alfabeta

Sanjaya, Wina. 2008. Pembelajaran dalam Implementasi Kurikulum Berbasis Kompetensi. Jakarta: Kencana

Trianto. 2010. Mendesain Model Pembelajaran Inovatif-Prograsif. Jakarta : Prenada Media 